\title{
EPIDEMIOLOGY AND OUTCOME AMONG SEVERE SEPSIS AND SEPTIC SHOCK PATIENTS IN A SOUTH INDIAN TERTIARY CARE HOSPITAL
}

\author{
MERIN BABUa, VIDYA P. MENON ${ }^{b}$ UMA DEVI P. a $^{*}$ \\ aDepartment of Pharmacology, Amrita School of Pharmacy, Amrita Vishwa Vidyapeetham, Amrita University, Kochi, India, bDepartment of \\ Internal Medicine, Amrita Institute of Medical Sciences, Amrita University, Kochi, India \\ Email: umadevip@aims.amrita.edu
}

Received: 15 Jan 2017 Revised and Accepted: 31 Mar 2017

\section{ABSTRACT}

Objective: The objective of this research was to determine the prevalence of severe sepsis and septic shock and evaluate its outcome.

Methods: This was a prospective, observational study, in which adult patients with severe sepsis or septic shock were included. Relevant information was collected from medical records and the hospital information system.

Results: A total of 250 patients [mean age 57.2 y (range: 18 to 98 y)] was studied. The majority of the patients suffered from severe sepsis (81.2\%). Most of the episodes occurred in males (75.2\%). Major comorbidities included diabetes mellitus (51.2\%), hypertension (44.8\%) and chronic liver disease $(30.4 \%)$. One hundred and seventy-eight patients (147 patients with severe sepsis and 31 patients with septic shock) had a positive culture with urine being the main site of infection. One hundred and two patients (40.8\%) had a monomicrobial infection while seventy-six (30.4\%) patients had a polymicrobial infection. Within the monomicrobial infections, the gram negative organisms predominated (54\%). The mean hospital stay for patients with severe sepsis was $11.5 \mathrm{~d}$. Mortality was noted in 79 patients ( 40 patients with septic shock and 39 patients with severe sepsis).

Conclusion: The main causative pathogens were gram negative bacteria. Admissions meeting septic shock criteria have a high mortality rate Hence, it is imperative to identify patients who are at high risk and treat them promptly to reduce serious consequences.

Keywords: Severe sepsis, Septic shock, Mortality

(c) 2017 The Authors. Published by Innovare Academic Sciences Pvt Ltd. This is an open access article under the CC BY license (http://creativecommons.org/licenses/by/4.0/) DOI: http://dx.doi.org/10.22159/ijpps.2017v9i5.17102

\section{INTRODUCTION}

Sepsis is a leading cause of concern throughout the world due to its association with increased morbidity, hospitalizations and mortality [1-4]. Sepsis also adversely affects the quality of life of those individuals who survive it [5]. An inflammatory response to an infection is known as sepsis. When sepsis is associated with dysfunction of any of the organ system or failure of the circulation, it is known as severe sepsis or septic shock, respectively [6, 7]. The increased life expectancy of individuals (including those who are immune-compromised) and the surge seen with the utilization of invasive medical interventions are all important contributors to the high incidence of sepsis and its complications. International guidelines highlight the need for early identification of the condition and prompt implementation of the treatment, including antibiotics to reduce the serious consequences [8-13]. It has been observed that prompt administration of antibiotics and improve outcomes in patients with sepsis. Due to the scarcity of studies from the Indian subcontinent, the present study was undertaken to determine the prevalence and outcome in patients with severe sepsis and septic shock.

\section{MATERIALS AND METHODS}

The present prospective observational study involving 250 adult patients with a diagnosis of severe sepsis or septic shock as per guidelines was conducted at our hospital from April 2015-16 following ethical approval (Thesis review committee/Pharma/ $2015 / 20$ ). Since no patient contact was carried out, the need for informed consent was waived.

The following data were collected from the hospital charts using Amrita Hospital Information System: details about age, sex, comorbidities, serum haematological and biochemical tests, organ dysfunction, microbiological data, antibacterial utilization and outcome. Following scores were also calculated: patient performance scale (Zubrod Score) and Charlson co-morbidity index.

GraphPad Prism 5 software was used for statistical analysis. Data is presented as mean, standard deviation, number and percentage as applicable. The continuous variables were analyzed using MannWhitney or unpaired t test while for categorical variables Chi-square test was used. $\mathrm{P}<0.05$ was considered significant.

\section{RESULTS}

In our present study, 250 patients who satisfied the Surviving Sepsis Campaign guidelines were included. Out of this population, 203 patients $(81.2 \%)$ were diagnosed with severe sepsis and 47 patients $(18.8 \%)$ with septic shock. The majority of the patients $(75.2 \%)$ were male; the mean age was $57.2 \mathrm{y}$ (range 18 to $98 \mathrm{y}$ ). The majority of the patients had a single co-morbid condition. Diabetes mellitus was the most common co-morbid condition $(51.2 \%)$ followed by hypertension (44.8\%) and chronic liver disease (30.4\%). The majority of the patients $(75.6 \%)$ had a Charlson co-morbidity score $\geq 3$. Severe sepsis patients presented with chief complaints of fever $(47.8 \%)$ followed by abdominal pain $(30 \%)$ and difficulty in breathing $(29.1 \%)$ while septic shock patients mainly presented with fever (40.4\%) followed by difficulty in breathing (31.9\%) and vomiting $(23.4 \%)$. The mean temperature, respiratory rate, heart rate and oxygen saturation were $99.3^{\circ} \mathrm{F}, 23.4$ breaths/minute, 104 beats/minute and $95.6 \%$, respectively. The two groups did not differ significantly with respect to the above parameters. The mean systolic and diastolic blood pressures were lower in septic shock patients when compared to severe sepsis patients due to their persistent hypotension (115.2/65.9 mmHg and 131.4/75.3 $\mathrm{mmHg}$, respectively). Septic shock patients had an elevated mean lactate level (3.7 mmol/l) and altered mental status (36.2\%) compared to severe sepsis patients $(2.0 \mathrm{mmol} / \mathrm{l}$ and $13.8 \%$, respectively) [table 1]. 
Table 1: General characteristics of severe sepsis and septic shock patients

\begin{tabular}{|c|c|c|c|c|}
\hline Variable & Severe sepsis $(n=203)$ & Septic shock $(n=47)$ & Total $(n=250)$ & P-value \\
\hline \multicolumn{5}{|l|}{ Gender } \\
\hline Male & $156(76.8)$ & $32(68.1)$ & $188(75.2)$ & 0.2100 \\
\hline Female & $47(23.2)$ & $15(31.9)$ & $62(24.8)$ & \\
\hline Mean age $\pm S D$ & $56.9 \pm 14.6$ & $58.5 \pm 14.5$ & $57.2 \pm 14.6$ & 0.4695 \\
\hline \multicolumn{5}{|l|}{ Number of co-morbidities } \\
\hline 0 & $20(9.9)$ & $7(14.9)$ & $27(10.8)$ & 0.3157 \\
\hline 1 & $61(30)$ & $12(25.5)$ & $73(29.2)$ & 0.5394 \\
\hline 2 & $47(23.2)$ & $10(21.3)$ & $57(22.8)$ & 0.7824 \\
\hline 3 & $36(17.7)$ & $6(12.8)$ & $42(16.8)$ & 0.4117 \\
\hline 4 & $29(14.3)$ & $8(17)$ & 37 (14.8) & 0.6341 \\
\hline 5 & $8(3.9)$ & $3(6.4)$ & $11(4.4)$ & 0.4620 \\
\hline 6 & $2(1)$ & $1(2.1)$ & $3(1.2)$ & 0.5169 \\
\hline \multicolumn{5}{|l|}{ Co-morbidities } \\
\hline Diabetes mellitus & $102(50.2)$ & $26(55.3)$ & $128(51.2)$ & 0.6276 \\
\hline Hypertension & $91(44.8)$ & $21(44.7)$ & $112(44.8)$ & 1.000 \\
\hline Chronic liver disease & $65(32)$ & $11(23.4)$ & $76(30.4)$ & 0.2932 \\
\hline Chronic kidney disease & $41(20.2)$ & $8(17)$ & 49 (19.6) & 0.6887 \\
\hline Dyslipidemia & $34(16.7)$ & $9(19.1)$ & $43(17.2)$ & 0.6944 \\
\hline Charlson co-morbidity score $\geq 3$ & $152(74.9)$ & $37(78.7)$ & $189(75.6)$ & 0.8376 \\
\hline \multicolumn{5}{|l|}{ Chief complaints } \\
\hline Fever & $97(47.8)$ & $19(40.4)$ & $116(46.4)$ & 0.3621 \\
\hline Abdominal pain & $61(30)$ & $9(19.1)$ & $70(28)$ & 0.1337 \\
\hline Difficulty in breathing & $59(29.1)$ & $15(31.9)$ & $74(29.6)$ & 0.6996 \\
\hline Generalized weakness & $43(21.2)$ & $8(17)$ & $51(20.4)$ & 0.5235 \\
\hline Vomiting & $31(15.3)$ & $11(23.4)$ & $42(16.8)$ & 0.1790 \\
\hline \multicolumn{5}{|l|}{ Vital signs (mean \pm SD) } \\
\hline Temperature $\left({ }^{\circ} \mathrm{F}\right)$ & $99.3 \pm 1.5$ & $99.3 \pm 1.5$ & $99.3 \pm 1.5$ & 0.7481 \\
\hline Respiratory rate (breaths/min) & $23 \pm 4.4$ & $25 \pm 6.6$ & $23.4 \pm 4.9$ & 0.0849 \\
\hline Heart rate (beats $/ \mathrm{min}$ ) & $102.9 \pm 17.5$ & $109.1 \pm 22.4$ & $104 \pm 18.6$ & 0.0561 \\
\hline Oxygen saturation (\%) & $95.6 \pm 5.1$ & $94.5 \pm 10.9$ & $95.6 \pm 6.5$ & 0.8804 \\
\hline Systolic blood pressure (mmHg) & $131.4 \pm 25.7$ & $115.2 \pm 28.2$ & $128.4 \pm 28.2$ & 0.0002 \\
\hline Diastolic blood pressure ( $\mathrm{mmHg}$ ) & $75.3 \pm 16.3$ & $65.9 \pm 19.8$ & $73.5 \pm 17.4$ & 0.0008 \\
\hline Lactate $(\mathrm{mmol} / \mathrm{l})$ & $2 \pm 1.4$ & $3.7 \pm 3$ & $2.3 \pm 1.9$ & $<0.0001$ \\
\hline Altered mental status (\%) & $28(13.8)$ & $17(36.2)$ & $45(18)$ & 0.0003 \\
\hline
\end{tabular}

$\mathrm{n}=$ number of patients, SD=standard deviation. The values are presented as number (\%) of patients or as mean \pm SD, Respiratory dysfunction, coagulation abnormality and hepatic dysfunction were observed in $56.4 \%, 44 \%$ and $36 \%$ patients, respectively. The incidence of hyperbilirubinemia and thrombocytopenia was not significantly different between the two groups (table 2).

Table 2: Organ dysfunction seen in severe sepsis and septic shock patients

\begin{tabular}{|c|c|c|c|c|}
\hline Organ dysfunction & $\begin{array}{l}\text { Severe sepsis } \\
(n=203)\end{array}$ & $\begin{array}{l}\text { Septic shock } \\
(\mathrm{n}=47)\end{array}$ & $\begin{array}{l}\text { Total } \\
(\mathrm{n}=250)\end{array}$ & P-value \\
\hline Hyperlactemia (>1 mmol/l) & $166(81.8)$ & $45(95.7)$ & $211(84.4)$ & 0.0174 \\
\hline $\begin{array}{l}\text { Arterial hypoxemia } \\
\left(\mathrm{PaO}_{2} / \mathrm{FiO}_{2}<300\right)\end{array}$ & 107 (52.7) & $34(72.3)$ & $141(56.4)$ & 0.0145 \\
\hline $\begin{array}{l}\text { Coagulation abnormality } \\
(\text { INR }>1.5 \text { or } \text { aPTT }>60 \mathrm{~s})\end{array}$ & $83(40.9)$ & 27 (57.4) & $110(44)$ & 0.0393 \\
\hline $\begin{array}{l}\text { Hyperbilirubinemia } \\
\text { (Total bilirubin }>4 \mathrm{mg} / \mathrm{dL} \text { ) }\end{array}$ & $74(36.4)$ & $16(34)$ & $90(36)$ & 0.7564 \\
\hline $\begin{array}{l}\text { Thrombocytopenia } \\
(\mathrm{PLT}<100000 / \mu \mathrm{l})\end{array}$ & $72(35.5)$ & $17(36.2)$ & $89(35.6)$ & 0.9278 \\
\hline Arterial hypotension ( $\mathrm{SBP}<90 \mathrm{mmHg}$ ) $/ \mathrm{MAP}<70 \mathrm{mmHg} / \mathrm{SBP}$ decrease $>40 \mathrm{mmHg}$ ) & $14(6.9)$ & $19(40.4)$ & $33(13.2)$ & $<0.0001$ \\
\hline
\end{tabular}

aPTT=activated partial thromboplastin time, INR=international normalized ratio, $\mathrm{MAP}=$ mean arterial pressure, n=number of patients, $\mathrm{PaO}_{2} / \mathrm{FiO}_{2}=$ ratio of arterial oxygen partial pressure to fractional inspired oxygen, PLT=platelet, SBP=systolic blood pressure. Values represent the number (\%) of patients.

A larger proportion of patients (147 patients with severe sepsis and 31 patients with septic shock) had a positive culture with urinary tract being the main site of infection followed by a bloodstream/central line related infection and pneumonia (table 3). One hundred and two patients $(40.8 \%)$ had a monomicrobial infection while seventy-six (30.4\%) patients had a polymicrobial infection. Within the monomicrobial infections, the gram-negative organisms (54\%) predominated. Escherichia coli and Klebsiella pneumoniae were the main pathogens. Thirty percent patients received an empiric monotherapy at presentation to the emergency department. A higher proportion of septic shock patients received a carbapenem (table 4).
The mean values of creatinine, urea, aspartate aminotransferase, phosphorus, prothrombin time, international normalized ratio and activated partial thromboplastin time were significantly higher in patients with septic shock than severe sepsis. Hypoalbuminemia was seen among the severe sepsis and septic shock patients (mean albumin: 2.8 and $2.7 \mathrm{mg} / \mathrm{dL}$, respectively). The two groups did not differ with respect to other haematological or biochemical parameters.

Mortality was noted in 79 patients (40 patients with septic shock and 39 patients with severe sepsis). In case of septic shock patients, $80.9 \%$ of the patients had a hospital stay of $<10 \mathrm{~d}$ as their mortality 
rate was higher than the severe sepsis patients. The mean hospital stay in severe sepsis and septic shock patients were 11.5 and $6.1 \mathrm{~d}$, respectively. The mean intensive care unit (ICU) stays were shorter in septic shock patients ( $4.9 \mathrm{~d})$ while severe sepsis patients had a longer stay in ICU (5.2 d). The direct admission to ward among the severe sepsis patients were considerably longer than the septic shock patients ( 6.3 and $1.1 \mathrm{~d}$, respectively).
We also tried to study the factors associated with mortality among severe sepsis and septic shock patients. A Zubrod performance score of 4 , the presence of hyperlactemia, coagulation abnormality and bloodstream infection was associated with mortality among severe sepsis patients. In the case of septic shock patients, a Zubrod performance score of 4 , the presence of $\geq 3$ co-morbidities, hypothermia and coagulation abnormality were associated with mortality (table 5).

Table 3: Site of infection

\begin{tabular}{|c|c|c|c|c|}
\hline Suspected site of infection & Severe sepsis $(n=203)$ & Septic shock $(n=47)$ & Total $(n=250)$ & P-value \\
\hline Urinary tract & $71(35)$ & $16(34)$ & $87(34.8)$ & 0.3360 \\
\hline Bloodstream/catheter & $56(27.6)$ & $13(27.6)$ & $69(27.6)$ & 0.9919 \\
\hline Lungs (Pneumonia) & $29(14.3)$ & $5(10.6)$ & $34(13.6)$ & 0.5110 \\
\hline Skin/Soft tissue & $10(4.9)$ & $3(6.4)$ & $13(5.2)$ & 0.6852 \\
\hline Wound & $4(2)$ & $2(4.2)$ & $6(2.4)$ & 0.3564 \\
\hline Abdomen & $2(1)$ & $3(6.4)$ & $5(2)$ & 0.0172 \\
\hline
\end{tabular}

$\mathrm{n}=$ number of patients. The values represent a number (\%) of patients.

Table 4: Antibiotic therapy

\begin{tabular}{|c|c|c|c|c|}
\hline & Severe sepsis $(n=203)$ & Septic shock $(n=47)$ & Total $(n=250)$ & P-value \\
\hline \multicolumn{5}{|l|}{ Number of antibiotics } \\
\hline 1 & $59(29.1)$ & $16(34)$ & $75(30)$ & 0.5021 \\
\hline 2 & $99(48.8)$ & $16(34)$ & $115(46)$ & 0.0680 \\
\hline 3 & $32(15.8)$ & $8(17)$ & $40(16)$ & 0.8322 \\
\hline$\geq 4$ & $13(6.4)$ & $7(14.9)$ & $20(8)$ & 0.0532 \\
\hline \multicolumn{5}{|l|}{ Class of drug } \\
\hline Ureidopenicillins & $99(48.8)$ & $26(55.3)$ & $125(50)$ & 0.4183 \\
\hline Third generation cephalosporin & $88(43.3)$ & $16(34)$ & $104(41.6)$ & 0.2434 \\
\hline Carbapenems & $54(26.6)$ & $24(51)$ & $78(31.2)$ & 0.0011 \\
\hline Fluoroquinolones & $32(15.8)$ & $7(14.9)$ & $39(15.6)$ & 0.8823 \\
\hline Lincosamide-Clindamycin & $42(20.7)$ & $10(21.3)$ & $52(20.8)$ & 0.9288 \\
\hline
\end{tabular}

$\mathrm{n}=$ number of patients. The values represent a number $(\%)$ of patients.

Table 5: Risk factors associated with mortality in severe sepsis and septic shock patients

\begin{tabular}{|c|c|c|c|c|c|c|}
\hline \multirow[t]{2}{*}{ Characteristics } & \multicolumn{3}{|c|}{ Severe sepsis } & \multicolumn{3}{|c|}{ Septic shock } \\
\hline & Alive (164) & Expired (39) & P-value & Alive (7) & Expired (40) & P-value \\
\hline Male gender & $128(78)$ & $28(71.8)$ & 0.4053 & $3(42.9)$ & $29(72.5)$ & 0.1206 \\
\hline Age $>60 y$ & $73(44.5)$ & $18(46.2)$ & 0.8530 & $2(28.6)$ & $17(42.5)$ & 0.4885 \\
\hline$\geq 3$ co-morbidities & $65(39.6)$ & $10(25.6)$ & 0.1037 & $0(0)$ & $18(45)$ & 0.0239 \\
\hline Charlson co-morbidity index $\geq 3$ & $121(73.8)$ & $31(79.5)$ & 0.4602 & $4(57.1)$ & $33(82.5)$ & 0.1305 \\
\hline Zubrod performance score 4 & $130(79.3)$ & $37(94.9)$ & 0.0218 & $4(57.1)$ & $40(100)$ & $<0.0001$ \\
\hline Tachycardia & $127(77.4)$ & 35 (89.7) & 0.0854 & $7(100)$ & $33(82.5)$ & 0.2302 \\
\hline Tachypnea & $106(64.6)$ & $26(66.7)$ & 0.8109 & $5(71.4)$ & $29(72.5)$ & 0.9534 \\
\hline Leukocytosis & $102(62.2)$ & $21(53.8)$ & 0.3375 & $3(42.9)$ & $6(15)$ & 0.0840 \\
\hline Altered mental status & $21(12.8)$ & $7(17.9)$ & 0.4024 & $3(42.9)$ & $14(35)$ & 0.6898 \\
\hline Hyperthermia & $20(12.2)$ & $5(12.8)$ & 0.9149 & $2(28.6)$ & $2(5)$ & 0.0392 \\
\hline Leukopenia & $10(6.1)$ & $5(12.8)$ & 0.1491 & $0(0)$ & $3(7.5)$ & 0.4539 \\
\hline Hypothermia & 144 (87.8) & $34(87.1)$ & 0.9149 & $5(71.4)$ & $38(95)$ & 0.0392 \\
\hline Hyperlactemia & $129(78.7)$ & 37 (94.9) & 0.0184 & $7(100)$ & $38(95)$ & 0.5454 \\
\hline Arterial hypoxemia & $83(50.6)$ & $24(61.5)$ & 0.2192 & $6(85.7)$ & $28(70)$ & 0.3912 \\
\hline Coagulation abnormality & $59(35.9)$ & $24(61.5)$ & 0.0035 & $1(14.3)$ & $26(65)$ & 0.0123 \\
\hline Thrombocytopenia & $53(32.3)$ & $19(48.7)$ & 0.0543 & $3(42.9)$ & $14(35)$ & 0.6898 \\
\hline Arterial hypotension & $10(6.1)$ & $4(10.3)$ & 0.3569 & $2(28.6)$ & $17(42.5)$ & 0.4885 \\
\hline Positive culture & $116(70.7)$ & $31(79.5)$ & 0.2715 & $5(71.4)$ & $26(65)$ & 0.7405 \\
\hline \multicolumn{7}{|l|}{ Site of infection } \\
\hline Urinary tract & $58(35.4)$ & $13(33.3)$ & 0.8109 & $4(57.1)$ & $12(30)$ & 0.1621 \\
\hline Bloodstream & $39(23.8)$ & $18(46.1)$ & 0.0052 & $0(0)$ & $13(32.5)$ & 0.0762 \\
\hline Lungs & $22(13.4)$ & $7(17.9)$ & 0.4670 & $1(14.3)$ & $4(10)$ & 0.7344 \\
\hline
\end{tabular}

The values represent number (\%) of patients

\section{DISCUSSION}

Although the study was limited to evaluation of only 250 patients, it reflects a strikingly higher mortality rate among the septic shock patients in a tertiary care hospital. Another finding of this study was the emergence of gram-negative organisms as the major pathogens in sepsis patients.

Male gender showed predominance over females for developing the infectious complications. A change in trend in a number of co- 
morbidities and incidence is emerging significance. In the present study, diabetes was the common co-morbid condition predisposing to infection due to abnormalities of host responses particularly neutrophil chemotaxis, adhesion and intracellular killings and defects in humoral immunity. Hypertension may induce left ventricular dysfunction with cardiac dilation that may also contribute to septic shock. Sepsis worsens liver failure in alcoholic patients with cirrhosis. Fever remained the chief complaint followed by breathlessness and abdominal pain at the time of diagnosis. Cellular hypoxia marked by hyperlactatemia develops significantly higher in septic shock than severe sepsis when there is an imbalance between the oxygen demand and consumption which leads to anaerobic metabolism.

Microbiological documentation is an essential criterion to make a diagnosis of the infection and hence the microbiological samples were evaluated at admission to the emergency department. The majority of the patients had a prior hospitalization along with risk factors of using mechanical ventilation, catheterization, a prior antibiotic therapy which leads to increased risk of infection and resistance among the patients. A major proportion of the patients had a positive culture with urinary tract being the predominant site of infection. This is in contrast to other studies $[14,15]$ which have reported lung as the major source of infection. Since ours is a tertiary care hospital, the majority of the patients have a history of prior hospitalization and urinary catheterization, which may be the reason for the present observation.

Gram-negative organisms remained the major pathogens in our study which is in accordance with earlier studies $[14,15]$. Antibiotic resistance is emerging as a serious problem due to inappropriate antibiotic use in both grams negative and gram positive organisms. Appropriate antibiotic administration on admission to the emergency department has been reported to improve the quality of life and survival among the patients [9, 10]. In view of the emergence of gram-negative organisms, especially the multidrug resistant strains, there is an urgent requirement for antimicrobial stewardship programs $[16,17]$. In the present study, septic shock patients had a higher mortality rate. The observed mortality rate appears to be higher than those reported earlier $[14,18,19]$. The exact reason for this observation is not known. We did not check the compliance with sepsis resuscitation and management bundles which could have given us a clearer picture. Another limitation of our study was that it was carried out only in a single centre, so the results are not necessarily representative for other centres.

\section{CONCLUSION}

Septic shock patients had a higher mortality rate. In these patients, a Zubrod performance score of 4 , the presence of $\geq 3$ co-morbidities, hypothermia and coagulation abnormalities was associated with mortality. The main causative pathogens were gram negative bacteria. Since admissions meeting septic shock criteria have a high mortality rate, it is imperative to identify patients who are at high risk and treat them promptly to reduce serious consequences.

\section{ACKNOWLEDGEMENT}

This study was supported by a grant from the Kerala State Council for Science, Technology and Environment.

\section{AUTHOR CONTRIBUTION}

Merin Babu participated in data collection, statistical analysis, interpretation of data and drafting of the manuscript.

Vidya P Menon participated in the study design, interpretation of data and revising of the manuscript critically for important intellectual content.

Uma Devi P participated in the study design, statistical analysis, interpretation of data, drafting and revising of the manuscript for important intellectual content.

\section{CONFLICT OF INTERESTS}

Declared none

\section{REFERENCES}

1. Stehr SN, Reinhart K. Sepsis as a global health problem-why we need a global sepsis alliance. Shock 2013;39 Suppl 1:3-4.

2. Harikesh Maurya, Susheel Kumar Dubey, Poonam Bisht, Monika Semwal, Sanjay Gandhi. An updates on the sepsiscausing multiple organ dysfunctions. J Crit Rev 2016;3:31-40.

3. Suarez De La Rica A, Gilsanz F, Maseda E. Epidemiologic trends of sepsis in western countries. Ann Transl Med 2016;4:325.

4. Hall MJ, Williams SN, DeFrances CJ, Golosinskiy A. Inpatient care for septicemia or sepsis: a challenge for patients and hospitals. NCHS Data Brief 2011;62:1-8.

5. Maley JH, Mikkelsen ME. Short-term gains with long-term consequences: the evolving story of sepsis survivorship. Clin Chest Med 2016;37:367-80.

6. Dellinger RP, Levy MM, Rhodes A, Annane D, Gerlach H, Opal SM, et al. Surviving sepsis campaign: international guidelines for management of severe sepsis and septic shock. Crit Care Med 2013;41:580-637.

7. Ozdemir V, Hekim N. Innovation management? Orienting sepsis RandD and technology transfer towards stratified medicine. EBioMedicine J 2016;6:8-9.

8. Perman SM, Goyal M, Gaieski DF. Initial emergency department diagnosis and management of adult patients with severe sepsis and septic shock. Scand J Trauma Resusc Emerg Med 2012;20:41.

9. Ferrer R, Martin-Loeches I, Phillips G, Osborn TM, Townsend $\mathrm{S}$, Dellinger RP, et al. Empiric antibiotic treatment reduces mortality in severe sepsis and septic shock from the first hour: results from a guideline-based performance improvement program. Crit Care Med 2014;42:1749-55.

10. Yokota PK, Marra AR, Martino MD, Victor ES, Durão MS, Edmond MB, et al. Impact of appropriate antimicrobial therapy for patients with severe sepsis and septic shock--a quality improvement study. PLoS One 2014; 9:e104475.

11. Beardsley JR, Jones CM, Williamson J, Chou J, Currie-Coyoy $\mathrm{M}$, Jackson T. Pharmacist involvement in a multidisciplinary initiative to reduce sepsis-related mortality. Am J Health Syst Pharm 2016;73:143-9.

12. Fan SL, Miller NS, Lee J, Remick DG. Diagnosing sepsis-the role of laboratory medicine. Clin Chim Acta 2016;460:203-10.

13. Lu J, Wang X, Chen $Q$, Chen M, Cheng L, Dai L, et al. The effect of early goal-directed therapy on mortality in patients with severe sepsis and septic shock: a meta-analysis. J Surg Res 2016;202:389-97.

14. Zhou J, Qian C, Zhao M, Yu X, Kang Y, Ma X, et al. Epidemiology and outcome of severe sepsis and septic shock in intensive care units in mainland China. PLoS One 2014;9:e107181.

15. Khwannimit B, Bhurayanontachai R. The epidemiology of, and risk factors for, mortality from severe sepsis and septic shock in a tertiary-care university hospital setting. Epidemiol Infect 2009;137:1333-41.

16. Aishwarya J Ramalingam. Carbapenemases and gram-negative bacteria: a review. Asian J Pharm Clin Res 2016;9:18-9.

17. Abhishek Pratap Singh, Usha Gupta, Saumya Das. Monitor the use of antibiotics in intensive care units with a special focus on restricted antibiotics in tertiary care hospital of India. Asian J Pharm Clin Res 2016;9:256-9.

18. Sep net critical care trials group. The incidence of severe sepsis and septic shock in German intensive care units: the prospective, multicentre INSEP study. Intensive Care Med 2016;42:1980-9.

19. Koonrangsesomboon W, Khwannimit B. Impact of positive fluid balance on mortality and length of stay in septic shock patients. Indian J Crit Care Med 2015;19:708-13.

\section{How to cite this article}

- Merin Babu, Vidya P Menon, Uma Devi P. Epidemiology and outcome among severe sepsis and septic shock patients in a South Indian tertiary care hospital. Int J Pharm Pharm Sci 2017;9(5):256-259. 